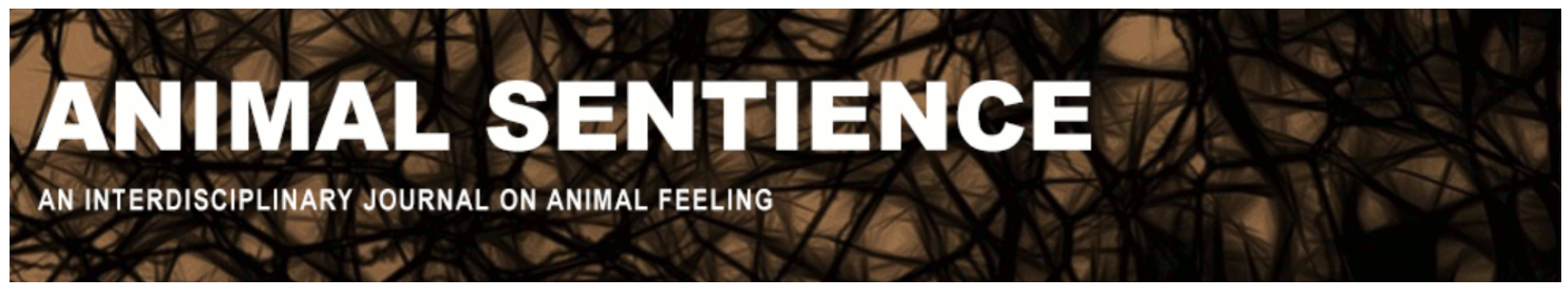

Wehbe, Yzar S. and Shackelford, Todd K. (2020) Appealing to human intuitions to reduce animal abuse. Animal Sentience 30(25)

DOI: $10.51291 / 2377-7478.1663$

Date of submission: $2020-12-04$

Date of acceptance: 2020-12-04 (c) 


\title{
Appealing to human intuitions to reduce animal abuse
}

Commentary on Wiebers \& Feigin on Covid Crisis

\author{
Yzar S. Wehbe \& Todd K. Shackelford \\ Department of Psychology, Oakland University
}

\begin{abstract}
Social scientists may be able to find ways to positively affect people's evolved moral compasses, thereby doing the planet and its inhabitants a great kindness. They could help to shape a constituency that is increasingly opposed to animal abuse in its largest-scale manifestations, factory farming and wet markets. This would, in turn, motivate people to elect ethical leaders who view inaction with regard to animal abuse as a serious moral and medical mistake, if only indirectly due to factory farming's exacerbation of the threats zoonoses pose to humans.
\end{abstract}

\begin{abstract}
Yzar S. Wehbe is a Ph.D. student in psychology at Oakland University. At Brunel University London, she earned a MSc in evolutionary psychology. She worked at USAID as a program evaluator in her home nation of Lebanon, as well as in effective altruism as a researcher with Animal Charity Evaluators.
\end{abstract}

Todd K. Shackelford is Co-Director of the Evolutionary Psychology Laboratory, Oakland University, and Editor of Evolutionary Psychology and Evolutionary Psychological Science. Much of his research addresses sexual conflict in humans. Website

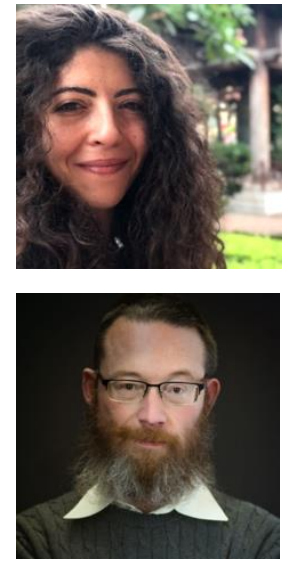

We advocate for a reduction in the demand for animals as food. Why? Not only because it is the ethical thing to do for the sake of all sentient beings (Singer, 1975), but also because factory farming and wet markets exacerbate the risk of zoonoses, which can be fatal to millions of humans (Wiebers \& Feigin, 2020; W\&F). Democratic governments are unlikely to mandate positive change unless their constituents demand that change. Nonetheless, organizations like the United Nations could incentivize progress in reducing the demand for animals as food. This can take the form of positive competition - for example, a "World Cup" where countries are judged on who can present the most thoughtful animal-friendly policies and laws. Rewards could take many other forms, such as "debt-for-nature" swaps where a portion of the national debt is forgiven in exchange for initiatives that protect global interests (see Bergstrom, 2020).

Our knowledge of human nature may be helpful in devising strategies to reduce meat consumption. This task will vary in difficulty across cultural groups. For example, it may be easier to get Jains and Brahmins to reduce meat consumption because most animal food products are already prohibited by religious edict (Kwon \& Tamang, 2015; Tobias, 1993). But in countries such as China, where eating a wide variety of animals is rewarded with status (Zhang et al., 2008), more work may be needed to reduce meat consumption.

Psychologists have noted that "[I]t would be a surprise if our brains were not strongly shaped by their hundreds of millions of years of interaction with other species." (Tooby and Cosmides, 2015 , p. 49). Humans' animal-related intuitions are characterized by biases for learning about the danger of animals (rather than other kinds of information about animals), as well as 
superior memory for danger-related information (Barrett \& Broesch, 2012). Humans possess further intuitions about animal properties (Boyer and Barrett, 2015). Atran and colleagues have found that humans universally categorize living beings into different taxa and hierarchies (Atran, 1998; López, Atran, Coley, Medin, \& Smith, 1997). These categories afford inductive inferences. For example, when two species are perceived to be close in taxonomic structure, we infer that the traits characterizing one species are likely to characterize the other. There is also evidence that the category "predator" is evoked by contextual cues that the animal "eats animals" (Barrett, 2015).

One strategy to reduce meat consumption consists of leveraging such folk psychological and biological intuitions, especially those relevant to zoonotic diseases (Atran, 1998). According to the social intuitionist model, most moral decision-making results from unconscious processes driven by intuitions (Bargh \& Chartrand, 1999), followed only later by deliberative reasoning to justify decisions after the fact (Haidt, 2001; Mercier and Sperber, 2017). Strategies for influencing behavior that assume people to be rational agents often backfire (e.g., Lewandowsky et al., 2012), whereas strategies that assume people are moralistic agents driven by intuitions are often successful (e.g., see the experiment related to the PalestinianIsraeli conflict by Ginges et al., 2007).

Elsewhere we have discussed marshaling the emotion of disgust to curb the endorsement of factory farming (Wehbe and Shackelford, 2020). This could be done, for example, by depicting factory farmed animals as being forced to eat food that is covered in their own feces. In their commentary, Davis et al. (2020) mention a specific psychological trait in this context, discovered by Tapp and colleagues (2018): the latter found that participants perceived "diseases" (i.e. zoonoses) in wild game as more threatening if they believed that the disease was transmissible across more distantly related taxa as opposed to closely related taxa (birdmammal as opposed to mammal-mammal). While Davis and colleagues contend that this effect is the result of the ability to "harness the power of human generalization (inductive reasoning)", another possibility is that this effect may be an example of a folk biological intuition about zoonoses. This intuition may be leveraged to deter humankind from actions that encourage factory farming and wet markets. Social scientists would benefit from continuing to investigate psychological intuitions related to factory farming and wet markets - especially those that may be leveraged to affect the behavioral changes championed by Weibers \&Feigin (2020).

We may be able to use intuitions and universal features of human moral psychology to target attitudes towards factory farming - arguably the most pressing problem at the intersection of zoonotic threats and animal abuse (Karesh et al., 2012). For example, we could create plans that reward humans socially whenever they preserve (rather than disrupt) other animals' species-typical behaviors and habitats. We could devise ways to encourage humans to moralize acts of omission in the same way that they moralize acts of commission (see DeScioli et al., 2012). This might, for example, take the form of a globally televised game show in which world leaders are rewarded for fair and utilitarian answers to ethical dilemmas including ones about animals raised for food. Given the colossal importance and scale of animal meat consumption and, in turn, factory farming and wet markets, many converging strategies will be needed. Targeting and leveraging pre-existing human intuitions will be a useful part of this plan. 


\section{References}

Atran, S. (1998). Folk biology and the anthropology of science: Cognitive universals and cultural particulars. Behavioral and Brain Sciences, 21, 547-611.

Barrett, H. C. (2015). Adaptations to predators and prey. In D. M. Buss (Ed), The Handbook of Evolutionary Psychology (2 ${ }^{\text {nd }}$ Ed., Vol. 1, pp. 246-286). New Jersey: Wiley.

Barrett, H. C., \& Broesch, J. (2012). Prepared social learning about dangerous animals in children. Evolution and Human Behavior, 33, 499-508.

Bargh, J. A., \& Chartrand, T. L. (1999). The unbearable automaticity of being. American Psychologist, 54(7), 462-479.

Bergstrom, B. J. (2020). Re-engage with the world for global health and animal welfare. Animal Sentience 30(22).

Boyer, P., \& Barrett, H. C. (2015). Intuitive Ontologies and Domain Specificity. In D. M. Buss (Ed), The Handbook of Evolutionary Psychology (2 ${ }^{\text {nd }}$ Ed., Vol. 1, pp. 161-182). New Jersey: Wiley.

Davis, T., Ireland, M. E., Van Allen, J., \& Worthy, D. A. (2020). Zoonotic realism, computational cognitive science and pandemic prevention. Animal Sentience 30(23).

DeScioli, P., Asao, K., \& Kurzban, R. (2012). Omissions and Byproducts across Moral Domains. PLoS ONE, 7(10), e46963. doi:10.1371/journal.pone.0046963

Ginges, J., Atran, S., Medin, D., \& Shikaki, K. (2007). Sacred bounds on rational resolution of violent political conflict. Proceedings of the National Academy of Sciences, 104(18), 7357-7360.

Haidt, J. (2001). The emotional dog and its rational tail: A social intuitionist approach to moral judgement. Psychological Review, 105(4), 814-834.

Karesh, W. B., Dobson, A., Lloyd-Smith, J. O., Lubroth, J., Dixon, M. A., Bennett, M., ... \& Machalaba, C. C. (2012). Ecology of zoonoses: natural and unnatural histories. The Lancet, 380(9857), 1936-1945.

Kwon, D. Y., \& Tamang, J. P. (2015). Religious ethnic foods. Journal of Ethnic Foods 2(2) 45-6.

Lewandowsky, S., Ecker, U. K., Seifert, C. M., Schwarz, N., \& Cook, J. (2012). Misinformation and its correction: Continued influence and successful debiasing. Public Interest, 13(3), 106-131.

López, A., Atran, S., Coley, J., Medin, D., \& Smith, E. (1997). The tree of life: Universals of folkbiological taxonomies and inductions. Cognitive Psychology, 32, 251-295.

Mercier, H., \& Sperber, D. (2017). The Enigma of Reason. Harvard University Press.

Singer, P. (1975). Animal Liberation. New York: Avon Books.

Tapp, W. N., Miller, M. F., Gaylord, N., Goldwater, M. B., Ireland, M. E., Van Allen, J., \& Davis, T. (2018). The Impact of Beliefs About Cross-Species Disease Transmission on Perceived Safety of Wild Game Meat: Building a Psychological Approach to Meat Safety. Meat and Muscle Biology, 1(2), e0186969.

Toates, F. (2020) Covid-19, evolution, brains and psychology. Animal Sentience 30(21).

Tobias, M. (1993). Jainism and Ecology: Views of Nature, Nonviolence, and Vegetarianism. The Bucknell Review, 37(2), 138.

Tooby, J., \& Cosmides, L. (2015). The theoretical foundations of evolutionary psychology. In D. M. Buss (Ed), The Handbook of Evolutionary Psychology (2 ${ }^{\text {nd }}$ Ed., Vol. 1, pp. 1-87). New Jersey: Wiley.

Wehbe, Y. S., \& Shackelford, T. K. (2020). [Review of the book Objection: Disgust, Morality, and the Law by D. Lieberman and C. Patrick]. Politics and the Life Sciences, 39(2), 237-238.

Wiebers, D., \& Feigin, V. (2020). What the COVID-19 crisis is telling humanity. Animal Sentience 30(1).

Zhang, L. J., Ning, H. \& Shan, S. (2008). Wildlife trade, consumption and conservation awareness in Southwest China. Biodiversity and Conservation, 17, 1493-1516. 